\title{
As responsabilidades dos entes federados contratualizadas no âmbito de uma região de saúde
}

\author{
Responsibilities of federated entities contracted within a health region \\ Las responsabilidades de las entidades federadas contratadas en una región de salud
}

Rommer Fabiano Mont-Morency Rosado Vieira ${ }^{1}$

\begin{abstract}
RESUMO: O Contrato Organizativo de Ação Pública na Saúde foi instituído pelo Decreto Presidencial $\mathrm{n}^{\circ} \mathbf{7}$ 7.508/2011 com o propósito de servir como um contrato entre entes políticos no âmbito de uma Região de Saúde. Ele se propõe a definir as responsabilidades de cada ente assumidas pelos respectivos chefes de executivo e secretários de saúde, além do Ministério da Saúde. Entretanto, suas características estão ora mais próximas de um convênio ou consórcio, ora mais próximas de um contrato. A força e a necessidade desse novo instrumento são discutidas, tendo em vista a existência de outros instrumentos já previstos para a regionalização cooperativa. Para o presente estudo foi realizada uma revisão bibliográfica sobre o tema e uma análise da legislação relacionada e confecção de uma minuta de contrato proposta para as regiões de saúde.
\end{abstract}

Palavras-chave: Saúde. Sistema Único de Saúde. Regionalização.

ABSTRACT: The Organisational contract of Public Health Action was established by the Presidential Decree No. 7.508/2011 for the purposes of serving as a contract between political entities within a Health Region. It defines the responsibilities to be delegated to the head of the executive branch and its undersecretary of health, as well as the Ministry of Health. However, its provisions are closer to an agreement or consortium, and, not rarely, those of a contract. The effectiveness and the need for such an instrument are discussed in the light of the existence of similar instruments previously adopted for cooperative regionalization. In order to analyze the main assumptions, a literature review and a review of related legislation were made, as well as a draft contract proposal for health regions.

Keywords: Health. Unified Health System. Regional Health Planning.

RESUMEN: El Contrato Organizativo de Acción Pública en la Salud fue instituido por el Decreto Presidencial no 7.508 / 2011 con el propósito de servir como un instrumento legal entre los entes políticos en el ámbito de una Región de Salud. Se propone definir las responsabilidades de cada ente que son legalmente delegadas a los jefes del ejecutivo y los secretarios de salud, así como las del Ministerio de Salud. Sin embargo, sus provisiones están más próximas a las del convenio o consorcio, o mismo parecidas a las de un contrato. La ejecutividad y la necesidad de este nuevo instrumento son discutidas, teniendo en cuenta la existencia de otros instrumentos ya previstos para la regionalización cooperativa. Para el presente estudio se realizó una revisión bibliográfica sobre el tema y un análisis de la legislación relacionada, así como la confección de un proyecto de propuesta de contrato para las regiones de salud.

\footnotetext{
${ }^{1}$ Especialista em Direito Sanitário. E-mail: rommer.vieira@saude.gov.br
} 
Palabras Ilave: Salud. Sistema Único de Salud. Regionalización.

\section{Introdução}

O direito sanitário é uma área do conhecimento multidisciplinar, que visa estudar as questões sanitárias sob a perspectiva do direito, e o direito à saúde é um dos atributos essenciais do direito à vida, aparecendo na Constituição de 1988 como um dos pressupostos do Estado brasileiro, ao lado de outros direitos como o direito à liberdade, à igualdade, à segurança e à propriedade.

O direito à saúde é garantido pelo Estado brasileiro mediante formulação e implementação de políticas públicas e prestação de serviços públicos que garantam acesso universal, igualitário e integral às ações e serviços de saúde (1). A garantia desse direito está positivada no artigo 196 da Carta Magna de 1988, bem como em regulamentação legal posterior, a exemplo da Lei Orgânica da Saúde, e em inúmeros outros esforços regulamentares infralegais como portarias do Ministério da Saúde e, recentemente, do Decreto Presidencial no 7.508/2011.

Para viabilizar essa garantia, o Sistema Único de Saúde (SUS) deve ser organizado e norteado segundo algumas diretrizes, positivadas no artigo 198, a saber: descentralização, atendimento integral e participação da comunidade. Elas implicam na necessidade de integração do sistema em uma rede regionalizada e hierarquizada e em uma melhor articulação intrafederativa. Tal necessidade de associação entre entes havia sido levantada por Mendes (2).

As Normas Operacionais e o Pacto Pela Saúde figuram na série de modelos de pactuação entre entes federados que já existiram dentro de uma perspectiva municipalista que predominava na época de suas concepções. Entretanto, mais estudos são necessários no sentido de se compreender as razões dos insucessos do municipalismo.

Um novo instrumento com a pretensão de estabelecer uma relação contratual entre entes políticos no âmbito de uma região de saúde², o Contrato Organizativo da Ação Pública (COAP), foi instituído por esse decreto, em que pese já existirem outros

\footnotetext{
2 "Espaço geográfico contínuo constituído por agrupamentos de Municípios limítrofes, delimitado a partir de identidades culturais, econômicas e sociais e de redes de comunicação e infraestrutura de transportes compartilhados, com a finalidade de integrar a organização, o planejamento e a execução de ações e serviços de saúde" (3).
} 
instrumentos estabelecidos, a exemplo das associações públicas ou pessoas jurídicas de direito privado que constituem os consórcios.

O objetivo do presente artigo é discutir as características do COAP e analisar as responsabilidades dos entes federados que assinam este contrato, com vistas a identificar os mecanismos de responsabilização dos gestores pelas metas pactuadas.

\section{Metodologia}

Este trabalho foi desenvolvido por meio de uma revisão bibliográfica e análise documental. Para alcançar o objetivo proposto foram analisados prioritariamente a Constituição Federal de 1988, a Lei Orgânica da Saúde, o Decreto Presidencial nº 7.508/2011 e a Lei dos Consórcios Públicos, além do modelo de COAP com seus anexos, visando identificar as responsabilidades assumidas pelos entes federados contratrualizados em uma região de saúde a partir da assinatura do COAP, bem como sobre os instrumentos de cooperação intrafederativa.

Tratou-se de uma pesquisa complexa tendo em vista à escassez e fragmentação teórica de material confiável para o estudo da contratualização advinda com a publicação do Decreto $7.508 / 2011$.

\section{Resultados}

O SUS segue princípios e diretrizes próprias e nesses mais de 20 anos de existência evoluiu com várias regulamentações. Na tentativa de alcançar seus objetivos, o sistema vivenciou uma fase de intenso municipalismo, seguido do fortalecimento do pensar regional de sua organização. Essa regionalização, fruto da necessidade de economia de escala e escopo e das características dos entes da nossa federação, fez surgir arranjos regionais específicos como as Regiões de Saúde.

Tendo em vista a responsabilidade solidária entre os entes federados, prevista no artigo 23, II, da CF, a diretriz da descentralização, prevista no artigo 198 da CF, busca definir as responsabilidades entre os entes federados com transferência de poder decisório, de recursos e de gestão de prestadores para estados e municípios (4).

A regionalização, segundo Paim (5), representa a articulação intergestores na implementação de políticas, ações e serviços de saúde com vistas a garantir acesso, integralidade e resolutividade na atenção à saúde da população. "Significa organizar os 
serviços de saúde em cada região para que a população tenha acesso a todos os tipos de atendimento" (5). A hierarquização, por sua vez, diz respeito à busca do ordenamento do sistema por níveis de atenção e pelo estabelecimento de fluxos assistenciais entre os serviços, de modo a regular o acesso aos mais especializados (6)

Essas diretrizes e princípios devem ser seguidos por todos os municípios, estados, Distrito Federal e União. Não se admitindo em nossa federação que o governo federal obrigue os demais entes a realizar qualquer ação em seu território sob o risco de ruptura do pacto constitucionalmente estabelecido (4).

Entretanto, constitui um desafio para a articulação intrafederativa a compatibilização da atuação das esferas de governo brasileiras, ao mesmo tempo autônomas e solidariamente responsáveis pela prestação de serviços de saúde, e do exercício do governo autônomo com a interdependência entre governos, tendo em vista complexidade que envolve os cuidados e prestações de saúde, que extrapolam os limites geográficos, orçamentários e políticos dos entes federados. Para superar tal complexidade, os arranjos intrafederativos são necessários e vários destes já existem em nosso ordenamento jurídico.

Pouco tempo depois da promulgação da Carta Constitucional de 1988, a Lei Orgânica da Saúde, em 1990, veio iniciar a regulamentação do SUS. As duas décadas seguintes à publicação da Lei Orgânica da Saúde foram marcadas por regulamentações através de portarias e outros atos normativos que, além de deixarem uma lacuna jurídica, geraram uma insegurança jurídica (7).

Paralelamente à evolução da regulamentação específica do SUS, aconteceu à das relações associativas intrafederativas, culminando na Lei dos Consórcios ${ }^{3}$, em 2005 . Essa lei dispõe sobre a contratação de consórcios públicos, instrumento de associação intrafederativa.

Na saúde, para preencher esse espaço e aprimorar a regulamentação do SUS, a Presidente Dilma Rousseff assina, em junho de 2011, o Decreto Presidencial no 7.508/2011. Esse decreto regulamenta a Lei no 8.080/1990, em especial quanto à organização do SUS, o planejamento da saúde, a assistência à saúde e a articulação intrafederativa. Dentre as inovações que esse decreto trouxe, consta um instrumento de

\footnotetext{
${ }^{3}$ Lei № 11.107 de 04 de abril de 2005.
} 
contratualização entre entes federativos cujo objetivo maior é organizar o sistema. Trata-se do Contrato Organizativo da Ação Pública da Saúde (COAP) definido como:

\begin{abstract}
um acordo de colaboração firmado entre entes federativos com a finalidade de organizar e integrar as ações e serviços de saúde na rede regionalizada e hierarquizada, com definição de responsabilidades, indicadores e metas de saúde, critérios de avaliação de desempenho, recursos financeiros que serão disponibilizados, forma de controle e fiscalização de sua execução e demais elementos necessários à implementação integrada das ações e serviços de saúde (3).
\end{abstract}

A estrutura de uma minuta de COAP foi apresentada e aprovada na $11^{\text {a }}$ Reunião Ordinária da Comissão Intergestores Tripartite de 15 de dezembro de 2011. As contratualizações entre entes federados no âmbito de uma região de saúde deverão basear-se nessa minuta, sem detrimento de futuros aperfeiçoamentos.

As ações e serviços desenvolvidos pelo Sistema Único de Saúde (SUS) na busca da concretização do direito à saúde envolvem a participação da União, dos estados, do Distrito Federal e dos municípios. A competência em prestar serviços de atendimento à saúde ficou com os municípios, em que pese contarem com a cooperação técnica e financeira da União e dos estados (8).

Tais iniciativas do Estado brasileiro para a prestação de serviços de saúde convergem para e devem se articular em um mesmo espaço territorial contínuo denominado região de saúde.

O Conselho Nacional de Secretários de Saúde (CONASS) afirma que "é preciso estabelecer a abrangência das ações e serviços e a responsabilidade dos respectivos gestores do SUS ao definir as Regiões de Saúde" (3).

Atualmente, o Brasil possui 435 Regiões de Saúde (9) constituídas pelos estados, em articulação com seus municípios, por meio de Resoluções pactuadas nas Comissões Intergestores Bipartite (CIB). É importante ressaltar que até agora não existem regiões de saúde interestaduais.

Portanto, um pensar regional da saúde se mostra necessário, tendo em vista as questões sanitárias ultrapassarem as capacidades das gestões municipais. Outra necessidade é a de se registrar os acordos e pactuações firmadas pelos entes e gestores. 
Nesse sentido, o COAP surge como mais um instrumento, cabendo destacar que outros instrumentos de contratualização já existem há muito tempo em nosso ordenamento jurídico, a exemplo dos consórcios e convênios, entretanto foram pouco utilizados.

Cabe ressaltar que, no modelo inicial de assistência municipalista (2), o município expande a assistência à saúde sem nenhuma articulação regional, pulverizando recursos públicos e gerando brutais ineficiências. A quebra desse paradigma de municipalização autárquica veio com o advento do paradigma da regionalização cooperativa que propõe o reconhecimento de "um espaço privilegiado, a microrregião de saúde, onde os municípios da microrregião sanitária, em associação entre si e com apoio da União e da Secretaria Estadual de Saúde" (2), fazem a gestão compartilhada da saúde.

Mendes \& Silva (2) assim vislumbraram esse arranjo intrafederativo sanitário:

Ao se associarem, os municípios da microrregião devem constituir um sistema microrregional de serviços de saúde - sob a forma de uma rede de atenção à saúde -, com base na cooperação gerenciada, gerando, pela sua ação solidária, um excedente cooperativo. Ademais, a regionalização cooperativa, ao associar municípios contíguos, reconstitui uma escala adequada para a oferta, econômica e de qualidade, dos serviços de saúde.

Esse paradigma da regionalização cooperativa baseia-se no "princípio da cooperação gerenciada, em que o componente da cooperação é dado pela associação intermunicipal" (2) e outro componente, o gerencial, "explicita-se em mecanismos de planejamento, controle e avaliação compartilhados de redes microrregionais de atenção à saúde" (2).

Ainda segundo Mendes \& Silva (2), o paradigma da regionalização cooperativa não apresenta semelhante na experiência internacional e, em razão disso, deverá ser construído em nosso País.

O Contrato Organizativo de Ação Pública da Saúde (COAP), anunciado como instrumento de gestão juridicamente mais seguro (7), pretende organizar o sistema e definir claramente as responsabilidades sanitárias e de financiamento da União, dos estados e dos municípios no âmbito de uma região de saúde.

Para além do COAP, outras formas de agregação intrafederativa como os consórcios e convênios são possíveis (8).

Além disso, a natureza peculiar organizativa do COAP reafirma a regionalização das ações e serviços públicos de saúde e a necessidade do desenvolvimento regional como 
caminho viável para a garantia do direito à saúde, fato que não pode ser conseguido por nenhum dos entes da federação isolada e desarticuladamente, ou seja, nenhum município "por si só será capaz de garantir ao seu munícipe todas as suas necessidades de saúde, devendo buscar a integralidade da atenção à saúde dentro do sistema de saúde" (9).

A palavra contrato pode ser entendida como o vínculo jurídico das vontades de partes interessadas com vistas a um objeto específico (10). Etimologicamente vem de contrahere e conduz a contractus, que significa ajuste, convenção ou pacto, sendo um acordo de vontades criador de direitos e obrigações. "Contrato é o acordo de vontade entre duas ou mais pessoas com a finalidade de adquirir, resguardar, modificar, transferir ou extinguir direitos" (10).

Os contratos da Administração, segundo Di Pietro (11), incluem todos os contratos celebrados pela Administração Pública, seja qual for o regime de direito.

Di Pietro (11) define contrato administrativo como os

ajustes que a Administração, nessa qualidade, celebra com pessoas físicas ou jurídicas, públicas ou privadas, para a consecução de fins públicos, segundo regime jurídico de direito público.

Os contratos administrativos seguem alguns princípios gerais, dentre os quais tem-se: presença da Administração Pública como Poder Público; finalidade pública, obediência à forma prescrita em lei; procedimento legal; natureza de contrato de adesão, natureza intuitu personae; presença de cláusulas exorbitantes e mutabilidade (11).

As chamadas cláusulas exorbitantes refletem a posição de superioridade da administração pública na relação estabelecida por um contrato administrativo. Entretanto, a outra parte signatária não perde sua autonomia em consensuar ou não o vínculo (12). As normas gerais dos contratos administrativos estão presentes na Lei no 8.666/1993.

São duas, portanto, as modalidades de contratos administrativos que Administração pode firmar: os contratos administrativos propriamente ditos e os contratos administrativos atípicos ou contrato de direito privado. Nesse, a Administração está de certa forma nivelada com a outra parte signatária, sendo regido pelo regime jurídico de direito privado (12). 
Já os contratos organizativos visam a promoção de uma estrutura de bens e a organização do esforço de pessoas para o desempenho de atividades de interesse comum (13).

Nessa linha, Santos (9) considera que o contrato organizativo busca uma finalidade única, não pretendendo as partes envolvidas (os entes federativos) nenhum proveito além da melhora de seu desempenho público. A vantagem está no resultado obtido pela soma das partes que passam a ter suas obrigações, responsabilidades e financiamento melhor definidos e explicitado.

Segundo Aguiar (7), pode-se afirmar ainda que o COAP garantirá uma gestão compartilhada possuidora de segurança jurídica, maior transparência e solidariedade entre os entes federativos.

O termo consórcio vem da expressão latina consortiu que tem o significado de associação, ligação, união (14). As atividades a serem realizadas em regime de consorciamento são regidas pelo princípio da cooperação entre os entes federados.

Inicialmente, fazia-se a distinção entre Consórcio Público, que significavam necessariamente a criação de uma nova pessoa jurídica, e Consórcio Administrativo, que era uma organização administrativa municipal despersonalizada (14). Já para Vianna (14) não havia tal distinção, sendo ambas as expressões sinônimas e significando os acordos firmados entre estatais, autarquias ou para-estatais de mesma espécie.

A Lei Federal no 11.107/2007 sepultou a discussão sobre a necessidade dos consórcios serem ou não dotados de personalidade jurídica ao estabelecer que os mesmos constituam uma associação pública ou pessoa jurídica de direito privado.

Sobre os consórcios públicos, posiciona-se Di Pietro (11):

Do exposto decorre que o chamado consórcio público passa a constituir-se em nova espécie de entidade da Administração Indireta de todos os entes federados que dele participarem. Embora o art. 6ํㅗ só faça essa previsão com relação aos consórcios constituídos como pessoas jurídicas de direito público, é evidente que o mesmo ocorrerá com os que tenham personalidade de direito privado. Não há como uma pessoa jurídica política (União, Estados, Distrito Federal e Municípios) instituir pessoa jurídica administrativa para desempenhar atividades próprias do ente instituidor e deixá-la fora do âmbito de atuação do Estado, como se tivesse sido instituída pela iniciativa privada. 
Com relação aos convênios, Justein Filho (13) afirma que neles:

Duas ou mais pessoas políticas podem disciplinar o exercício conjugado de atribuições, definindo fins comuns a serem atingidos por meio da aplicação coordenada de recursos próprios. Não há interesses contrapostos entre os partícipes. A atuação jurídica não se consubstancia em permuta de bens. Ao contrário, verifica-se homogeneidade de interesses. Cada associado colabora para obtenção do fim comum, exercitando atividades que se enquadram na própria competência ou desempenhando atribuições que, teoricamente, enquadrar-se-iam em competência alheia. Enfim, diversas pessoas estatais reúnem esforços e recursos para prestação de determinado serviço que interessa a todas elas.

Ainda segundo Justein Filho (12), todas as "hipóteses de conjugação de esforços administrativos entre entes políticos federais distintos pressupõem uma espécie de convênio, ainda que implícito".

Portanto, o COAP mais se assemelha aos convênios que aos consórcios. Ele não se enquadra como um contrato administrativo típico, ficando dentro do grupo dos contratos organizativos. O Decreto Presidencial no 7.508/2011 trouxe essa tentativa de inovação jurídica no sentido de melhor organizar o sistema através de contratos organizativos. Entretanto, consideramos o COAP dentro do grupo dos convênios e estes, conforme Di Pietro (11), não constituem uma modalidade contrato e objetivam interesses comuns.

Nosso pacto federativo define a necessidade de cooperação e de complementariedade entre os entes (4), devendo a responsabilidade solidária garantir a prestação de serviços públicos.

A responsabilidade civil dos entes estatais decorrente da prestação dos serviços de saúde é sempre objetiva. Essa responsabilidade objetiva do Estado "implica averiguar se o dano teve como causa o funcionamento de um serviço público" (11). Não podendo, portanto, o Poder Público furtar-se a reparação os danos causados aos administrados quando não possui uma máquina pública suficientemente organizada e com isso não concretiza o direito à saúde do paciente de ser atendido na espera de cuidado de saúde.

Para além da responsabilidade civil do Estado existe a administrativa, a penal e a sanitária. Esta foi prevista pela Constituição federal de 1988 e através de processo legislativo será instituída em nosso ordenamento jurídico (7) como uma lei de responsabilidade sanitária. 
Segundo Mendes (2), a responsabilização inequívoca pela saúde da população deverá ser facilmente identificável no SUS. Com essa identificação das responsabilidades federativas feitas, os cidadãos poderão "se localizar nas agendas da saúde, votar com mais consciência e exercitar melhor o controle social" (2).

$\mathrm{Na}$ regionalização cooperativa, essa responsabilização inequívoca deve ser conseguida pela definição de competências, minimizando os conflitos, permitindo que os diferentes atores sociais do SUS saibam "quem é responsável por quais ações, o que é fundamental para que o SUS seja um espaço de construção democrática, tal como foi concebido juridicamente" (2).

Ficam a União, os Estados-membros, o Distrito Federal e os municípios com a de obrigação de promover a saúde pública de forma solidária (15). Dessa forma, cabe aos Chefes do Poder Executivo de cada um desses entes, e aos respectivos secretários de saúde, a responsabilidade pela gestão compartilhada da saúde pública.

Entretanto, as ações e serviços públicos de saúde integram uma rede regionalizada e hierarquizada constituindo um sistema único (8). A diretriz da descentralização não retira a responsabilidade da União e dos estados e nem tem como propósito sobrecarregar municípios. Ela redefine responsabilidades entre os entes (4). Arranjos regionalizados surgem em decorrência da concentração geográficas de serviços mais complexos, das diferenças de porte populacional e de condições político-institucionais de nossos entes federativos (4).

A integralidade, por sua vez, constitui um desafio que transcende a capacidade isolada da quase totalidade de nossos entes federados. Diferentemente da assistência social, onde até pode se falar em mínimos existenciais (16), viabilizados por meio de renda mínima, bolsa escola, etc., na saúde não se admite mínimos.

O padrão de integralidade, definido como uma escolha que a sociedade e o Poder Público podem fazer para estabelecer conjuntamente o rol de serviços que o SUS vai garantir a toda a sociedade (16), é um desafio para os diferentes entes federados e para o SUS. A Lei № 12.401/2011 redefiniu a assistência terapêutica integral como:

I - dispensação de medicamentos e produtos de interesse para a saúde, cuja prescrição esteja em conformidade com as diretrizes terapêuticas definidas em protocolo clínico para a doença ou o agravo à saúde a ser 
tratado ou, na falta do protocolo, em conformidade com o disposto no art. 19-P;

II - oferta de procedimentos terapêuticos, em regime domiciliar, ambulatorial e hospitalar, constantes de tabelas elaboradas pelo gestor federal do Sistema Único de Saúde - SUS, realizados no território nacional por serviço próprio, conveniado ou contratado." (3).

Estes fatores forçam o rompimento dos limites administrativos dos municípios, gerando uma interdependência significativa entre governos (4) dotados constitucionalmente de autonomia. O equilíbrio entre a autonomia e a interdependência dos governos pode ser alcançado por meio da coordenação intrafederativa (4) viabilizada pela articulação entre diferentes instâncias governamentais na gestão de políticas públicas de saúde.

O Decreto no 7.508/2011 e a Resolução CIT nํ 03/2012 estabelecem que o objeto do COAP será a integração e a interação das ações e serviços de saúde dos entes federativos de uma Região de Saúde em rede de atenção à saúde.

No modelo sugerido de COAP, podemos encontrar quatro tipos de responsabilidades: organizativas, executivas, orçamentárias e financeiras e as de monitoramento, avaliação de desempenho e auditoria.

As responsabilidades organizativas dizem respeito à organização do sistema no âmbito da região de saúde. Trazem os princípios e diretrizes do SUS, as diretrizes sobre a conformação de redes de atenção à saúde, a integralidade e programação das ações e serviços, ao controle social, ao acesso ordenado, à articulação intrafederativa, governança, monitoramento, avaliação de desempenho, publicidade e auditoria, financiamento e sanções administrativas (7).

As responsabilidades executivas são baseadas nas diretrizes nacionais de saúde, estabelecidas na XIV Conferência Nacional de Saúde, realizada em 2011, sendo de cumprimento obrigatório pelos entes signatários. Diretrizes estaduais poderão ser incorporadas. Cada diretriz apresenta objetivos regionais a serem alcançados e medidos por metas regionais plurianuais e anuais definidas para determinados indicadores. A parcela de responsabilidade de cada município da região de saúde no alcance de tais metas é explicitada. Como anexos do COAP estão o Mapa da Saúde, a Relação Nacional 
de Ações e Serviços de Saúde (RENASES), a Relação Nacional de Medicamentos Essenciais (RENAME) (3).

Os indicadores presentes no COAP são classificados em universais, específicos e complementares, conforme estejam ou não definidos para todas as regiões de saúde (3).

As responsabilidades orçamentárias e financeiras expressam os compromissos orçamentários e financeiros assumidos por cada ente para a viabilização do alcance das metas regionais.

As responsabilidades de monitoramento, avaliação de desempenho e auditoria serão executados pelos entes federativos, individualmente ou não, na região de saúde. Já o prazo de vigência do COAP é de 04 anos, preferencialmente.

A partir dessas responsabilidades contratualizadas e definidas regionalmente para a União, os estados, o Distrito Federal e os municípios, acredita-se num ganho em organização do sistema que, por sua vez, refletirá em aumento da qualidade dos serviços de saúde e na garantia de que o direito à saúde estará sendo buscado de forma mais eficiente.

As sanções previstas no COAP para os entes são apenas administrativas, sendo definido na cláusula décima-quinta que o descumprimento de qualquer das cláusulas e condições previstas no COAP será objeto de discussão na Comissão Intergestores Regional (CIR) e/ou na Comissão Intergestores Bipartite (CIB).

Norteia essa discussão o alcance da regularização da situação mediante termo aditivo que disporá sobre prazos e formas de cumprimento das cláusulas e condições contratuais não cumpridas, quando então o ente signatário responsável pela transferência de recursos financeiros em relação à cláusula em condição não cumprida, deverá ser ouvido obrigatoriamente nas comissões intergestores.

Assim, no caso de descumprimento do COAP, uma comunicação formal dessa situação à CIR e à CIB poderá ser feita por qualquer dos entes signatários. Essas comissões ficam encarregadas da notificação dos entes inadimplentes para que os mesmos apresentem as suas justificativas (3).

Seja qual for a situação de descumprimento das cláusulas, condições e programações do COAP, haverá a participação de todos os entes signatários na CIR e na CIB para a devida negociação. 
O COAP proposto ainda estabelece um fluxo para os dissensos nas comissões intergestores:

I - em caso de dissensos na CIR, os entes signatários deste contrato, poderão encaminhar recurso à $\mathrm{CIB}$, com clara argumentação contida em exposição de motivos; e

II - permanecendo a discordância em relação à decisão da CIB quanto ao recurso, os entes signatários poderão encaminhar o recurso à CIT;

III- As Comissões Intergestores deverão observar o prazo de até 45 dias contados a partir da data do protocolo para tramitação, análise, discussão e posicionamento sobre o dissenso;

IV - Transcorrido o prazo sem apreciação, os signatários poderão enviá-lo para a instância seguinte (3).

Persistindo o descumprimento dentro dos novos prazos estabelecidos no termo aditivo, o ente que não justificar a sua falta, terá os recursos correspondentes à sua situação identificada suspenso. Ainda segundo a Minuta COAP, a realocação dos recursos será pelo período correspondente ao descumprimento apurado e em valores que correspondam às ações e aos serviços não executados.

Durante essa realocação de recursos, um plano de atendimento à saúde da população do território relacionado será discutido na CIR/CIB. Nessa ocasião, definem-se quais (ou qual), entes federativos ficarão responsáveis pelo recebimento dos recursos durante o prazo de inadimplência contratual. Segue-se a esta definição a realocação dos recursos, na região de saúde ou no Estado, após o esgotamento das tentativas de reajustamento.

Caso seja constatada impropriedade ou irregularidade da aplicação de recursos, o resultado da auditoria será encaminhado à autoridade competente para providências cabíveis, bem como comunicado às comissões intergestores. Outros encaminhamentos são possíveis, mas não foram especificados na Minuta do COAP.

\section{Considerações finais}

Mesmo com o advento do paradigma da regionalização cooperativa, a integração e a articulação entre ações de atenção básica, de média e de alta complexidade e os níveis de governo de nossa federação persistem como um desafio para a organização do sistema ainda presente. A concretização da regionalização cooperativa exige, portanto, arranjos intrafederativos pactuados e acordados. 
$\mathrm{Na}$ busca dessa articulação intrafederativa, várias formas de agregação intrafederativa são possíveis e estão disponíveis há muito tempo em nosso ordenamento jurídico e os convênios e consórcios são exemplos disso. Portanto, não necessariamente haveria a necessidade de se pensar em uma nova forma jurídica, pois os instrumentos disponíveis antes do COAP, a exemplo dos consórcios públicos, poderiam ser já suficientes para dar um caráter contratual aos compromissos assumidos pelos entes federados no âmbito de uma região de saúde com vistas à regionalização cooperativa.

Seja qual for o instrumento, a necessidade de mecanismos de associação e contratualização intrafederativa integrados em um processo de regionalização cooperativa já havia sido defendida por Mendes antes mesmo do advento da Lei dos Consórcios e do COAP. Neste ponto e diante dessa necessidade, mais estudos são necessários para se compreender as razões da baixa utilização de todos esses instrumentos.

No entanto, a natureza jurídica confusa do COAP pode não colaborar para a responsabilização dos entes pelos compromissos assumidos. Além disso, a expressão contrato não está sendo utilizada em seu sentido primordial, pois o COAP não se configura num contrato de fato, tendo em vista as características discutidas anteriormente.

Por outro lado, o COAP é descrito como um "contrato" organizativo e não um contrato comutativo, ou seja, um acordo de vontades gerador de direitos e obrigações para as partes contratantes (SANTOS, 2011). Sendo assim, o COAP também não se enquadra como consórcio público, pois não há a partir de sua assinatura a criação de uma personalidade jurídica, embora também tenha o mesmo propósito dos consórcios públicos de "estabelecer relações de cooperação federativa, inclusive a realização de objetivos de interesse comum" (VIANA, 2008, p.5).

Portanto, o COAP mais se assemelha aos convênios do que aos consórcios, pois representa "um acordo de colaboração firmado entre entes federativos" (BRASIL, 2011).

Quanto à sua maior segurança jurídica, a expressão contrato carrega consigo um sentido de força que pode não estar presente em tais contratos organizativos, ainda mais que os tipos de responsabilidades e penalidades previstas no COAP ficam restritas à esfera administrativa, sendo resolvidas no âmbito das instâncias de governança intergestoras do SUS.

Seja qual for sua natureza jurídica, o que deve ser objeto de mais estudos, a contratualização proposta pelo Decreto $7.508 / 2011$ pretende ser um instrumento normativo 
que define a distribuição de funções e competências gestoras para um conjunto de entes mais particularmente interligados por externalidades sanitárias recíprocas.

O COAP surge como mais um instrumento para o SUS, entretanto, sua natureza precisa ser melhor definida no campo instrumentos de cooperação institucional intrafederativa. Da mesma forma, algumas responsabilidades, para além das previstas na minuta COAP, precisam ser explicitadas.

Outro ponto discutível e que merece mais estudos é a questão das penalidades a serem impostas aos entes políticos e aos gestores que assinam tal contrato. Elas não estão claras ou fortemente definidas na minuta, principalmente para os gestores, ficando restritas à esfera administrativa. Talvez uma lei de responsabilidade sanitária venha a responder este ponto, melhorando as penalidades propostas e responsabilizando de fato os gestores que assumem para seus entes políticos compromissos sanitários perante outros entes políticos e à própria sociedade.

Sendo assim, podemos questionar se o COAP traz consigo algum diferencial em relação aos instrumentos de cooperação intrafederativa já estabelecidos. Percebemos que de tempos em tempos o SUS é presenteado com instrumentos e modelos, fruto de novas ideias, para solucionar uma questão e com o passar dos anos e dos governos essa questão continua sem solução. Foi assim com os ciclos das Normas Operacionais e com o Pacto pela Saúde.

Isso nos leva a refletir se o COAP será insuficiente para os problemas do SUS. E, ainda, sobre como será o SUS, com ou sem o COAP, daqui a algum tempo e mais, sobre a necessidade de se investir em instrumentos que já existem ou na criação de novos instrumentos. Será esse realmente o problema? No Brasil tendemos a criar sempre uma lei ou um novo modelo e o problema nunca acaba sendo resolvido. Surge apenas uma nova regulamentação, um novo "pacote" da saúde e o problema persiste.

Dessa forma, entendemos que nossa federação já dispõe de mecanismos e instrumentos jurídicos e de planejamento suficientes para a cooperação dos entes políticos, cabendo aos gestores usá-los de fato para que o SUS possa proporcionar a grande promessa constitucional para a saúde. 


\section{Referências}

1.Delduque, MC.; Marques, SB. O Direito Social à saúde deve ser garantido por políticas públicas e decisões sociais. In: Temas Atuais de Direito Sanitário, Delduque, MC et al. (org.), Brasília: CEAD/FUB, 2009.

2.Mendes, EV. Silva, MVCP. Pacto de Gestão: da municipalização autárquica à regionalização cooperativa. Secretaria de Estado de Saúde de Minas Gerais. Belo Horizonte. 2004. 80 pags. Disponível na internet na URL:

http://www.saude.mg.gov.br/publicacoes/planejamento-gestao-em saude/livro_marcus_pestana.pdf. [Acesso em 15.out.2012].

3.Brasil. Conselho Nacional de Secretários de Saúde. Sistema Único de Saúde / Conselho Nacional de Secretários de Saúde - Brasília: CONASS, 2011. 224 p. Coleção Para Entender a Gestão do SUS 2011, v. 1.

4.Lima, LD. Federalismo, descentralização e regionalização na política de saúde do Brasil. In: Direito Sanitário, Asensi, FD et al. (org.), Rio de Janeiro: Elsevier, 2011, p. 131-161.

6 Quinellato, LV. A Diretriz de Hierarquização do SUS: mudando a antiga perspectiva do modelo médico assistencial privatista. Rio de Janeiro: Dissertação de Mestrado - FGV, Escola Brasileira de Administração Pública e de Empresas, 2009.

7. Aguiar, LOF. Contrato Organizativo da Ação Pública da Saúde: uma análise à luz do direito sanitário. Brasília: Monografia de Especialização - FIOCRUZ, Programa de Direito Sanitário, 2012.

9.Santos, L.; Andrade, LOM. Redes interfederativas de saúde: um desafio para o SUS nos seus vinte anos. Ciência \& Saúde Coletiva, Rio de Janeiro, 16:1671-1680, 2011.

10.Miranda, MB. Teoria Geral dos Contratos. Revista Virtual Direito Brasil, São Paulo, v. 2, p. 01-15, 2008. [Disponível na internet na URL:

http://www.direitobrasil.adv.br/index_arquivos/Page1897.htm. [ Acesso em 29.nov.2012]

12.Barchet, G. Direito Administrativo. Rio de Janeiro. Elsevier. 2009.

13. Justen Filho, M. Parecer sobre minuta de anteprojeto de Lei da Política Nacional de Saneamento Básico. Brasília. 2005.] Disponível na internet na URL:

http://www.planalto.gov.br/ccivil_03/revista/Rev_72/pareceres/saneamento_complementar_ MarcalJustenFilho_1.pdf. [ Acesso em 12.out.2012].

14. Viana, PR. A duplicidade de regimes jurídicos dos consórcios públicos em sua legislação reguladora e a sua incompatibilidade em face do sistema jurídico vigente. Porto Alegre. 2008. Disponível na internet na URL:

http://www.rzoconsultoria.com.br/artigo_desc.php?id=44. [ Acesso em 6.nov.2012].

15. Torres, FCD. Direito à saúde e a responsabilidade solidária dos entes federativos. Conteúdo Jurídico. 2012. Disponível na internet na URL: 
http://www.conteudojuridico.com.br/?artigos\&ver=2.35767\&seo=1. [ Acesso em 29.nov.2012]

8. Brasil. Constituição da República Federativa do Brasil de 8 de outubro de 1988. Brasília: Senado Federal, 2011.

16. Santos, Lenir. O Direito à Saúde no Brasil. Campinas. Saberes. 2010.

11. Di Pietro, MSZ. Direito Administrativo. São Paulo. Atlas. 2011.

5.Paim, JS. O que é o SUS. Rio de Janeiro: Fiocruz, 2002

9. Brasil. Lei federal $n^{\circ} 11401$ de 28 de abril de 2012. Disponível na internet na URL: http://www.planalto.gov.br/ccivil_03/_Ato2011-2014/2011/Lei/L12401.htm. [ Acesso em 28.nov.2012]

Recebido em: 5.6.2017 Aprovado em:23.7.2017 